\title{
NOTCH SIGNALING: A POTENTIAL THERAPEUTIC TARGET IN PROSTATE CANCER
}

M.A. Villaronga ${ }^{1}$, C.L. Bevan ${ }^{2}$ and B. Belandia ${ }^{1, *}$

${ }^{1}$ Departamento de Biología del Cáncer, Instituto de Investigaciones Biomédicas, Consejo Superior de Investigaciones Científicas, Arturo Duperier 4, 28029 Madrid, Spain

${ }^{2}$ Androgen Signalling Laboratory, Department of Oncology, Imperial College London, Hammersmith Hospital, London W12 0NN, United Kingdom

*Address correspondence to this author at the Departamento de Biología del Cáncer, Instituto de Investigaciones Biomédicas, Consejo Superior de Investigaciones Científicas, Arturo Duperier 4, 28029 Madrid, Spain

Tel: +34 91585 4453; Fax: + 3491585 4401; email: bbelandia@iib.uam.es

Keywords: androgen receptor, Notch pathway, prostate cancer, gamma-secretase inhibitors 


\begin{abstract}
The Notch pathway and the endocrine system constitute two key biological signaling mechanisms, responsible for cell-to-cell communication between adjacent cells and long-distance hormonal signals respectively. They play central roles during the development of higher eukaryotic organisms but they also take part in the regulation of many aspects of adult physiology and homeostasis. The contribution of defects in the normal transmission of hormone-dependent signals to the development of endocrine cancers has been widely analyzed and the knowledge derived from these studies has allowed us to develop many successful therapeutic strategies. However, in many cases these hormonal treatments become ineffective despite the fact that cancer cells maintain normal expression levels of wild-type hormone nuclear receptors. Less is known about the involvement of altered Notch signaling in the origin and progression of cancer, although there is clear evidence indicating that deregulation of Notch activity occurs in several types of tumors, including highly prevalent hormone-dependent types of cancer such as breast, ovarian and prostate cancer. This review will summarize accumulating data suggesting that Notch signaling plays a key role in the control of proliferation, differentiation and survival of prostate epithelial cells. Notch signals are required for normal prostate development and homeostasis, and abnormalities in Notch signaling may be critical during the development of prostate cancer. We will also discuss the possible oncogenic role for alterations in the crosstalk mechanisms between Notch and androgen-dependent signals during tumorigenesis in the prostate and how they could influence the outcome of anti-cancer hormonal treatments.
\end{abstract}




\section{INTRODUCTION}

The prostate is an exocrine gland of the male mammalian reproductive system, the primary function of which is to produce seminal fluids and it is also required for bladder control and normal sexual functioning. The development and homeostatic maintenance of the prostate are both regulated by an interplay between endocrine hormones, paracrine signals and local cell-cell interactions that modulate the specific genetic pathways controlling cell proliferation and differentiation (reviewed in [1]). Alterations in these complex regulatory networks contribute to the abnormal cell physiology responsible for benign prostate hyperplasia $(\mathrm{BPH})$, prostatic intraepithelial neoplasia (PIN) and malignant prostate tumors [2-4]. Prostate cancer (PC) is the most frequently diagnosed neoplasm and the second leading cause of cancer-related death in men in western countries [5], therefore much effort has been devoted to studying its etiology and to developing effective therapies against this disease. The prostate consists of glandular epithelium surrounded by fibromuscular stroma. Over $90 \%$ of prostate tumors arise within the glandular epithelial cell compartment [6]. For that reason, the elucidation of the molecular mechanisms that regulate epithelial cell proliferation and differentiation is an essential step towards understanding the basis of oncogenic transformation in the prostate gland. Among the endocrine hormones, androgens play a pivotal role in PC etiology because they are required for prostate epithelial cell growth and survival of both normal and malignant tissues [7, 8].

Prostate epithelium is composed of two histologically distinct layers, a basal cell layer and a luminal secretory cell layer. There are at least three distinct major cell types in prostate epithelium [9-11]: basal cells, found underlying basal membrane; differentiated luminal cells that produce prostatic secretory proteins; and neuroendocrine cells scattered between the basal and luminal layers that secrete 
neuroendocrine peptides. The basal layer is the proliferative compartment of the prostate epithelium and there is a small subpopulation of basal cells that are thought to be true pluripotent stem cells [12-14]. These stem cells give rise initially to the so-called transit-amplifying cells that undergo further proliferation and differentiation to intermediate epithelial cells that will finally generate the terminally differentiated luminal secretory cells.

Responsiveness of normal and transformed prostate cells to androgenic stimulation is determined by the expression of the androgen receptor (AR), a member of the nuclear receptor (NR) superfamily of ligand-dependent transcription factors [15]. Basal and transit-amplifying cells do not express androgen receptors and intermediate cells express AR protein at a very low level, however, all these cells require critical levels of androgen-stimulated paracrine growth factors for their proliferation but not for survival [11]. AR expression increases all along epithelial cell differentiation process reaching a maximum level in terminally differentiated luminal secretory cells. Luminal cells are non-proliferating but require constant androgen stimulation for survival [16]. Thus, androgen signaling plays a pivotal role in the control of growth, function and proliferation of prostate epithelial cells. Androgens are not tumorigenic per se, but they are essential for the growth and perpetuation of tumor cells, hence androgensuppressing strategies have been widely used for the management of PC since the pioneering works of Huggings and Hodges in the early 1940s (reviewed in [17]). The most common PC therapy is androgen elimination combined with antiandrogen treatment (termed maximal androgen blockade). However, most prostate tumors eventually become insensitive to this treatment and recur. The majority of such tumors continue to express AR but they are refractory to antiandrogen therapy. One of the fundamental challenges for researchers studying PC is understanding the pathways that 
lead to the transition to such so-called androgen independent prostate cancer (AIPC). Several mechanisms have been proposed to explain the appearance of AIPC including mutations in $\mathrm{AR}$, changes in the levels of $\mathrm{AR}$ and/or its coactivators and ligandindependent activation of AR through crosstalk with other signaling pathways (reviewed in [7, 18-20]). Several major signaling pathways have been shown to affect AR function, such as growth factor receptor signaling, Mitogen activated protein kinase signaling (MAPK), cytokine signaling and Wnt signaling (reviewed in [21]). In recent years accumulating evidence suggests that another major signaling pathway, Notch signaling, might be tightly intertwined with androgen signaling, contributing directly to the regulation of prostate gland development and function. In addition, several experimental observations indicate that aberrations in the expression of components of the Notch signaling pathway and/or alterations in the molecular mechanisms of crosstalk between Notch signals and AR may have a role in the origin and development of PC. The purpose of this review is to highlight these recent evidences linking Notch and AR regulatory axes and to discuss the possible role for Notch signaling as a potential PC therapeutic target.

\section{NOTCH SIGNALING}

\section{Overview of the Notch signaling pathway}

The Notch signaling pathway represents a major regulator of gene expression that plays a central role in cell fate decisions in metazoans, acting through local cell-cell interactions (reviewed in [22]). Notch ligands and receptors are single-pass transmembrane proteins with large extracellular domains. Thomas Hunt Morgan first identified notch in 1917 and the gene was named after the notches that appear at the end of wing blades of fruit flies lacking a gene copy. Notch receptors and their ligands have 
since been identified in virtually all metazoans. In mammals there are four different Notch receptors (NOTCH1-4, [23-27]) and five known Notch ligands named Deltalike1, -3 and -4 (DLL1, DLL3, DLL4, [28-30]) and Jagged1 and Jagged2 (JAG1 and JAG2, [31, 32]). The extracellular domains of all these proteins consist primarily of a variable number of epidermal growth factor (EGF)-like repeats responsible for the receptor-ligand interaction $[33,34]$. The Notch signaling pathway is initiated when receptor-bearing cells interact with Notch ligands present on adjacent cells. This leads to two consecutive proteolytic cleavage events in the Notch receptor. The first cleavage is catalyzed by a member of the ADAM (A disintegrin and metalloprotease) family of metalloproteases and it sheds the extracellular portion of the Notch receptor [35]. This is followed by the action of gamma-secretase that hydrolyzes a peptide bond within the transmembrane domain releasing the Notch intracellular domain (NICD), which then translocates to the nucleus [36]. There, NICD binds to a transcriptional regulator known as $\mathrm{CBF} 1 / \mathrm{Su}(\mathrm{H}) / \mathrm{LAG}-1$ (CSL). In the absence of NICD, CSL inhibits expression of target genes by recruiting transcriptional corepressors such as NCoR, SHARP and CtBP $[37,38]$. Interaction with NICD releases these corepressor complexes and allows the recruitment of transcriptional coactivators including MAML1 (mastermind-like 1) and histone acetyltransferases $[39,40]$. The effects downstream of the NICD-CSL interaction are not completely understood, but the best characterized target genes directly activated by NICD-CSL are members of the bHLH-orange superfamily of transcriptional repressors [41-43]. Upon Notch activation the expression of several members of this family increases and they modulate cellular responses by suppressing expression of downstream target genes, constituting a transcriptional regulatory cascade. This is a simplified model of the so-called "classical" Notch pathway, although there is evidence for other less understood CSL independent signaling pathways 
triggered by Notch activation designated the "non-classical" pathway. It is beyond the scope of this review to describe in detail the complexities of the Notch pathway.

\section{Notch function}

Notch signaling is an evolutionarily conserved mechanism that participates in the development of multicellular organisms during embryonic and postnatal development. Signals between adjacent cells mediated by Notch receptors are key players in cell fate determination, regulating processes such as lateral inhibition and lineage decision in tissues derived from all three primary germ layers. Thus, this juxtacrine pathway modulates in a precise way other short- and long-range signals required for normal development of the organism. During development, phenotypic differences arise in neighboring cells, caused by stochastic events, intrinsic or extrinsic factors. These subtle differences are stabilized and amplified through changes in expression of Notch ligands and receptors, and the downstream intracellular cascades triggered by the activation of Notch signals. In addition to their vital role during embryonic development, Notch signals regulate the equilibrium between stem-cell maintenance, binary cell-fate decisions and induction of differentiation required for homeostasis in self-renewing tissues in adult organisms. Due to historic reasons, the roles of Notch signaling during embryonic development have been particularly subject to extensive characterization, however, subsequent studies have also demonstrated a central role for Notch signals in the regulation of other important cellular processes including apoptosis, migration, and adhesion, further reinforcing the biological relevance of this cell-cell communication mechanism [44, 45].

It is noteworthy to mention that the Notch signaling cascade, although very simple in the basic core components responsible for the initiation of the signal, which are 
conserved through evolution, can be modulated by signal strength, timing, cell type and context. Therefore, Notch activation can have different or even opposing effects depending on the cellular context or its integration with other signaling pathways.

\section{The role of Notch in carcinogenesis}

Cancer comprises a group of diseases characterized by an abnormal development of cells proliferating in an uncontrolled way. The key role of Notch in the regulation of cell proliferation, differentiation and apoptosis make this pathway an obvious candidate to participate in the origin and/or progression of tumors when alterations in its normal function occur. The first evidence for an oncogenic role of Notch was identified in human T-cell acute lymphoblastic leukemia (T-ALL) [46]. The chromosomal translocation $\mathrm{t}(7 ; 9)$ in human T-ALL results in deregulated expression of a truncated, constitutively active NOTCH1 receptor lacking most of its extracellular domain. Recent studies have shown that activating mutations of NOTCH1 are present in more than $50 \%$ of human T-ALLs [47], supporting a critical role for NOTCH1 as an oncogene in this type of cancer (reviewed in [48]). The expression of constitutively active NOTCH4 receptors also causes mammary tumors in mice [26, 49] and activated NOTCH1 signaling contributes to the neoplastic phenotype in human RAS-transformed cells [50]. Although truncated forms of all four Notch receptors have transforming potential in vitro [51] and in animal models (reviewed in [52]), oncogenic Notch receptors do not usually have full transforming potential and they frequently collaborate with other oncoproteins during carcinogenesis.

To date, gain of function mutations in Notch receptors have not been found in human solid tumors. However there is increasing evidence that Notch signals are oncogenic in many tissues, and aberrant expression of Notch receptors, ligands, 
modulators and targets has been observed in a growing number of tumors, including highly prevalent types of cancer such as breast, lung, prostate, ovarian and pancreatic carcinomas [52-54].

In keeping with the great context-dependency of the outcome of Notch activation, Notch signaling in tumorigenesis is not always associated with an oncogenic role induced by its aberrant stimulation. There is clear evidence demonstrating that Notch can also act as a tumor suppressor in certain types of cancers $[52,53])$, particularly skin

cancer. In the epidermis, Notch signaling is required for keratinocyte growth arrest and entry into differentiation [55]. Moreover, conditional ablation of Notch1 in murine epidermis causes epidermal hyperplasia, skin tumors and facilitates chemical-induced skin carcinogenesis [56], and transgenic mice expressing a dominant negative form of MAML1, a pan-Notch inhibitor, develop cutaneous squamous cell carcinomas [57]. These observations indicate an antioncogenic role of Notch signaling in the epidermis. Whether this tumor suppressor role of Notch signaling is extended to other tissues remains to be established.

\section{NOTCH SIGNALING AND PROSTATE BIOLOGY}

\section{Notch signaling in prostate development}

The first evidences indicating that Notch signaling may be involved in prostatic development came from experiments performed with rodent models by Gao and colleagues [58]. The previously documented relevance of cell-cell interactions in the regulation of proliferation, differentiation and tumorigenesis of prostate epithelial cells $[6,59-61]$ prompted them to study a possible direct role for Notch signaling in the regulation of those processes. To do so, they first examined the expression patterns of Notch1 mRNA during rodent prostatic development, using quantitative RT-PCR 
analysis and in situ hybridization techniques. These studies on endogenous Notch expression were complemented with the characterization of mice containing a transgene of green fluorescent protein (GFP) under the control of the Notch1 promoter, wherein Notch1-expressing cells fluoresce green [62]. They found that Notch1 was expressed at high levels in the developing prostate at postnatal day 1 to postnatal day 10 , and its expression was down-regulated in adult animals. Before postnatal day 5 all cells in the prostatic epithelium possess progenitor cell characteristics, and they observed that all these proliferating cells express Notch1 together with cytokeratin-14, a marker for epithelial basal cells. From this homogeneous population, some epithelial cells undergo differentiation giving rise to the intermediate epithelial cell types and the terminally differentiated luminal epithelial cells, which lose cytokeratin 14 expression, whereas others remain proliferative and stay in the basal layer. Notch1 expression was only maintained in the basal cells, cytokeratin 14-positive cells, indicating that Notch expression is associated with the basal cell population. Therefore, NOTCH1 signaling might be involved in the acquisition of luminal versus basal cell identity in the prostatic epithelium. A similar restriction of NOTCH1 expression to progenitor cells has also been described in the nervous system, where NOTCH1 usually is expressed in neural progenitor cells but terminally differentiated neurons do not express Notch receptors [22]. This study was restricted to a single Notch receptor subtype, but the highly regulated dynamics of Notch1 expression strongly suggested a critical role for Notch signaling during prostatic development modulating prostate epithelial cell proliferation and differentiation.

Independent studies confirmed that expression of NOTCH1 receptor and its ligand Jagged1 is restricted to basal and immature intermediate prostate epithelial cells. Tran et al. characterized the phenotype and growth characteristics of human prostate 
epithelial cells growing in vitro [63]. They found that expression of prostate stem cell antigen (PSCA), a cell surface antigen expressed in normal prostate epithelial cells that is overexpressed in prostate tumors, is a unique marker of late transit-amplifying prostate epithelial cells. These cells co-express basal and secretory cytokeratins and have a phenotype intermediate between pure basal and secretory cells. Their analysis showed that expression of NOTCH1 and Jagged1 is absent in PSCA-positive cells, indicating that their expression is restricted to basal and early intermediate precursors. Therefore, transit-amplifying cells have heterogeneous phenotypes; NOTCH1 and Jagged 1 expression is only maintained in a subpopulation of early transit-amplifying cells but their expression is lost in more differentiated PSCA-positive cells.

Further support for a central role of Notch signaling in the control of prostate epithelial biology came from recent work by John T. Isaacs and co-workers [64, 65]. One of the fundamental constraints for PC research has been the lack of adequate in vitro human cell line models. Cells from prostate carcinomas have proven to be one of the most difficult cell types from which to establish cell lines. Seventeen human prostate carcinoma cell lines have been well-characterized [66], but most in vitro studies have been performed using the three earliest established prostate carcinoma cell lines, which either contain a mutation in the AR gene that creates a promiscuous AR able to bind to and be activated by other steroids (LNCaP), or do not express AR (DU 145 and PC-3). These cell models have contributed significantly to our understanding of prostate cancer, but they cannot help us to elucidate the molecular pathways responsible for the development of PC at its early stages or to explain the causes of the AIPC phenotype observed in PC cells still expressing wild-type AR. In attempts to circumvent this problem, several groups have established new prostate cancer cell lines from human primary prostate tumors using low calcium $(<300 \mu \mathrm{mol} / \mathrm{L})$, serum-free, growth factor- 
defined cell culture medium (that is in contrast to previously generated human PC cell lines that were originally established with and maintained in $10 \%$ fetal calf serum medium in which calcium is between 650 and $1,860 \mu \mathrm{mol} / \mathrm{L}$ ). Under these culture conditions it was documented that from all non-transformed prostate epithelial cell populations, only transit-amplifying cells survive and these can be propagated for up to 10 serial passages $[11,63,67]$. To test whether in those cell culture conditions the nontransformed transit-amplifying cells derived from normal contaminating prostate epithelium were outgrowing cancer cells, Isaacs' laboratory carried out a thorough characterization of prostate cell cultures derived from radical prostatectomy specimens [64]. As a result they observed that, in low calcium, serum-free, growth factor-defined medium, what grows are not truly prostatic cancer cells but basally derived normal transit-amplifying cells. One of the critical reasons that explains the selective outgrowth of the normal transit-amplifying versus cancer cells is the differential effect of lowcalcium conditions on the structure of NOTCH1 receptor. As discussed above, basal cells and early transit-amplifying cells express the receptor NOTCH1 and its ligand Jagged1. In low calcium medium, NOTCH1 receptor is conformationally in a constitutively active form allowing cell autonomous signaling independently of cell-cell interactions [68]. This ligand independent activation of Notch signaling contributes to the survival of transit-amplifying cells even in low cell density cultures. The addition of gamma-secretase inhibitors (GSIs) to prostate epithelial cell cultures, at concentrations that inhibit the production of the NICD transcription factor, was toxic, and there were no viable cells after 5 days of such treatment [64]. These results indicate that survival of prostate transit-amplifying cells requires unique NOTCH1 mediated signaling, strengthening the notion that Notch signals play an important role in the regulation prostate epithelial biology. Their results also suggest that transformed epithelial cells 
either do not express NOTCH1 receptor, or, because of the different cell-context, its activation is not sufficient to promote cell survival. At the 1 to $2 \mathrm{mmol} / \mathrm{L}$ physiological tissue calcium level, NOTCH1 signaling is not cell autonomous and it requires liganddependent activation. Under those conditions NOTCH1 signaling is no longer required for survival but instead contributes to stimulate proliferation of prostatic cancer cells. The authors of this study suggest that these characteristics are consistent with the ability of PC to metastasize to bone, a tissue with high calcium levels.

\section{Mechanisms of crosstalk between Notch and androgen signaling}

More evidence for a possible direct role for Notch signaling in modulating prostate physiology derived from biochemical studies performed to characterize the molecular mechanism of action of NRs. AR belongs to the NR superfamily of liganddependent transcription factors. The ability of NRs to activate gene transcription depends on the recruitment of coactivator protein complexes with enzymatic activities that reorganize chromatin. Amongst the best characterized are the p160 family of coactivators, SRC1/NCoA1, TIF2/ $\mathrm{NCoA} 2$ and AIB1/NCoA3 [69], which interact directly with ligand-bound NRs and serve as platform proteins recruiting both enzymes that catalyze posttranslational modifications [70] and ATP-dependent-chromatin remodeling complexes [71]. A yeast two-hybrid screen performed with the highly conserved bHLH-PAS N-terminal domain of SRC1 as bait identified a downstream target of Notch signaling, named HEY1 (hairy/Enhancer-of-split related with YRPW motif 1), as an SRC1-interacting protein [72]. Upon Notch activation, HEY1 expression is increased and it accumulates in the nuclei, acting as a transcriptional repressor of Notch target genes. Further functional characterization of this association demonstrated that HEY1 interacts directly with both SRC1 and the AR, and specifically represses 
transcription from AR-dependent promoters. Although SRC1 functions as a common coactivator for all NRs, HEY1 did not repress any of the other NRs tested. Another member of the HEY family that mediates Notch signaling, HEY2, was also able to specifically repress AR-dependent transcriptional activity. The mechanisms by which HEY1 and HEY2 repress AR, and the functional consequences of this interaction in vivo, remain to be elucidated. However, these in vitro experiments suggest that changes in endogenous levels of HEY1 in the cell, induced by Notch activation, have the potential to modulate cellular responses to testosterone, providing a molecular mechanism of coordination between long distance endocrine signals and cell-to-cell juxtacrine communication.

The negative feedback between androgen-dependent signals and Notch pathway may possibly occur in a reciprocal manner, based on recent gene profiling experiments described by Nantermet et al. [73]. To identify the androgen-responsive genetic pathways that regulate prostate cell division and differentiation they examined changes in global gene expression in the ventral prostate after DHT administration to androgendepleted rats. Among the transcripts expressed significantly differently they observed that AR stimulation repressed expression of Notch1 and its ligand Jagged1, also a negative regulator of Notch signaling, Sell1 [74], was induced, indicating that DHT might inhibit Notch signaling. Their results, on one hand, reinforce the idea that Notch signals play a role in the regulation of prostate cell growth and proliferation, and, on the other, suggest that in vivo AR stimulation modulates Notch signaling in the prostate gland in a negative way. This study, along with the reported repression of AR activity by HEY1, a Notch target [72], provides a mechanism for reciprocal negative feedback between androgen-dependent gene regulation and Notch. However, these large-scale 
gene expression analysis need to be validated by more experimental evidence and a detailed study of the prostate epithelial cell types involved in the crosstalk is lacking.

In light of recent results from Isaacs laboratory [65], the direct role of HEY1 as an AR corepressor may in part explain the molecular mechanisms by which activated Notch signaling regulates prostate epithelial cell growth and differentiation. Continuing with their characterization of several nonimmortalized and immortalized human prostate epithelial cell lines and the consequences of maintaining them in low-calcium medium (i.e., subject to continuous, cell autonomous, activation of NOTCH1 receptor), they studied the effects of NOTCH1 signaling on differentiation of intermediate cells in vitro. These cells fail to undergo full differentiation in vitro into mature, AR-expressing, luminal-secretory cells. Such inability is, at least in part, due to the continuous activation of NOTCH1 receptor that induces the expression of its downstream effector HEY1. HEY1 act as a transcriptional corepressor both for members of the family of GATA transcription factors $[75,76]$ and AR [72]. Thus, it has been proposed that HEY1 prevents the expression of GATA- and AR-regulated genes required for further differentiation of transit-amplifying cells into luminal-secretory cells. In agreement with this observation, human prostate cancer cell lines that are grown in high calcium containing medium do not express HEY1, which is consistent with their advanced luminal-secretory differentiation status [65].

\section{Mouse models}

The critical role of Notch signaling in the control of prostate cell growth and differentiation suggested by the previously discussed studies, performed using in vitro models, has recently been confirmed by using animal models in ex vivo and in vivo systems. Wang et al. established a transgenic mouse line in which Notchl-expressing 
cells can be selectively ablated [77]. Specific targeting was achieved by expressing the bacterial nitroreductase, an enzyme that catalyzes its substrate into a cytotoxin capable of inducing apoptosis, under the Notch1 promoter. Cells that express nitroreductase are selectively killed when exposed (in vitro or in vivo) to the prodrug CB1954. This experimental approach allowed them to target the cytotoxin to Notch1 expressing cells at various developmental time points using two systems: ex-vivo organ culture of early postnatal prostates, and in vivo re-growth of prostate in castrated mice following testosterone replacement. Their results showed that elimination of Notchl-expressing cells inhibited the branching morphogenesis, growth and differentiation of early postnatal prostate culture and impaired prostate regeneration triggered by hormone replacement in castrated mice. These observations reinforce the idea that NOTCH1expressing cells are important for prostate epithelial cell growth and proliferation and supported their hypothesis that NOTCH1-positive cells define progenitor cells in the prostate epithelium. In addition, they found that NOTCH1 mRNA expression was elevated in the prostate following castration but it returned to nearly normal levels after 3 days of hormone replacement, indicating that the proposed reciprocal negative feedback between Notch and androgen signaling $[72,73,78]$ may indeed occur in vivo.

Subsequent studies from the same laboratory further exploited the ex-vivo prostate culture model to investigate how inactivation of Notch signaling affects the growth of rat neonatal prostate [79]. To do so, they used inhibitors of gamma-secretase, the enzyme responsible for the proteolytic step that leads to the generation of NICD. These GSIs block the release of NICD and, as a result, prevent the expression of Notch downstream effectors $[36,80,81]$. Inactivation of Notch signaling in prostate explants greatly enhanced proliferation of prostate epithelial cells but prevented luminal cell differentiation. The majority of epithelial cells in prostates treated with GSIs co-express 
cytokeratins 8 and 14, indicating that they are immature progenitor cells and that segregation of cytokeratin 8-positive luminal and cytokeratin14-positive basal cells is inhibited. These effects on prostate epithelial cell proliferation and differentiation also resulted in profound morphologic alterations, causing reduced branching morphogenesis and enlarged epithelial tubules in GSI-treated prostate explants. Wang and colleagues also used a previously described interferon-inducible Notch1 gene deletion mouse model [82] to examine the effect of inactivation of Notch pathway on prostate growth and differentiation in vivo. Histological analysis was carried out using prostates harvested 3 weeks after Notch1 deletion (at a stage corresponding to postnatal days 3640). In Notch1 knockout mice, they observed several significant architectural changes, including increased tufting and bridging, and the normal columnar morphology of luminal epithelial cells or the laminal nature of basal cells was not properly maintained [79]. Moreover, in keeping with the results derived from ex vivo prostate explants, they observed an increased epithelial proliferation and enrichment in cell populations that coexpress luminal and basal cell markers. Both experimental approaches have drawbacks, because GSIs can affect other biological pathways modulated by gamma-secretases, and systemic effects on prostate physiology derived from deletion of Notch1 in all NOTCH1-expressing tissues cannot be ruled out, but taken together, these results suggest that Notch signaling (i) has an inhibitory role on prostate epithelial cell growth and expansion; and (ii) it facilitates proper luminal cell differentiation and epithelial layer segregation. Their findings clearly demonstrate that intact Notch signaling is required for correct prostate development, although the molecular mechanisms by which Notch signals modulate prostate cell proliferation and differentiation are still unknown. 


\section{NOTCH SIGNALING AND PROSTATE CANCER}

All the experimental evidence described in the previous section indicates that Notch signaling plays a key role in the control of proliferation, differentiation and survival of prostate epithelial cells. Nearly all prostate adenocarcinomas originate within this prostate cell population; therefore it is predictable that alterations in the correct function of Notch signaling may contribute to the origin and progression of prostate cancer. Indeed, since the early studies linking the Notch pathway to prostate physiology, most laboratories working in the field have also characterized the expression of components of this pathway in established prostate cancer cell lines and human tumor samples, trying to correlate these data with effects on prostate cancer cell growth in vitro and in vivo. Below we will summarize the aforementioned studies.

The initial identification of Notch1 regulated expression during murine prostate development prompted Shou and colleagues to examine the expression of Notchl in transgenic adenocarcinoma of the mouse TRAMP prostate cancer model [83]. These mice were generated by using the prostate luminal cell-specific rat probasin promoter to derive expression of the simian virus 40 large-tumor antigen coding region. Mice expressing the transgene display progressive forms of prostatic carcinomas with neuroendocrine features. In situ hybridization experiments showed that in TRAMP mice normal mature prostate Notchl expression is either undetectable or very low, but malignant and metastatic prostate cells express high levels of Notch1 [58]. A parallel study of Jaggedl expression revealed that it was not detectable in the malignant epithelial cells in TRAMP tumors or in normal prostatic epithelium in wild-type mice, suggesting that in those tumor cells Notch signaling is not physiologically activated, or that its activation rely on different ligands or crosstalk with other signaling pathways. Notch1 expression is associated with basal cell population during normal prostatic 
development, however, in the malignant cells of TRAMP, Notch1 expression is uncoupled from cytokeratin 14 , a basal cell marker. This result, together with the theoretical luminal-cell specific targeting of probasin promoter, indicate that the TRAMP luminal tumor cells could probably undergoing a dedifferentiation process, associated with increased proliferation and abnormally elevated Notch1 expression.

Shou and colleagues also examined expression of Notchl and its ligands in the established human prostate cancer cell lines (LNCaP, DU 145 and PC-3). Notch1 was expressed at various levels in these cell lines, showing the highest level in LNCaP cells. Conversely, expression levels of Notch ligands are low or undetectable in those cell lines. Interestingly, overexpression of the constitutively active form of NOTCH1 inhibited cell proliferation in all three prostate cancer cell lines [58]. Whether this reduction in the proliferation caused by NOTCH1 activation is due to an increase in the number of cells undergoing terminal differentiation and becoming mitotically inactive remain to be demonstrated. Another independent study showed that NOTCH1 and NOTCH2 mRNAs were expressed in prostate cancer cell lines (LNCaP, PC-3 and PC3M) whereas NOTCH3 and NOTCH4 mRNAs were not detected [84]. The Notch ligands Jagged1, Jagged2 and DLL1 were expressed in all three prostate cancer cell lines, and their expression levels were significantly higher in those cell lines relative to the levels observed in normal prostate cells (PNT2 cell line).

Another study has shown that among human prostate cancer cell lines, those with osteomimetic properties express higher levels of Notch1 expression [85]. Prostate cancer metastasizes preferentially to the skeleton and elicits osteoblastic lesions by unknown mechanisms [86], and it has recently been described that Notch signaling positively regulates osteoblastic cell differentiation [87]. Based on those evidences Zayzafoon and colleagues examined the role of Notch signaling during the development 
of osteomimetic properties of prostate cancer bone metastases [85]. They found that NOTCH1 expression is greatly increased (4-5 fold) in two osteoblastic skeletal prostate metastatic cancer cell lines (C4-2B and MDA-PCa-2b cells) when compared with nonskeletal metastatic cancer cell lines (LNCaP and DU 145). Immunohistochemical studies showed that NOTCH1 is also expressed in human clinical samples from osteoblastic prostate cancer metastasis. NOTCH1 ligand DLL1 was expressed at high levels only in C4-2B cells, suggesting that Notch signaling can be activated in this cell line without addition of exogenous factors. The expression of other Notch receptors and their ligands was also examined but showed no significant correlation between skeletal and nonskeletal metastatic cell lines. Using $\mathrm{C} 4-2 \mathrm{~B}$ cells as in vitro model to study mineralization in osteogenic medium they observed that the concomitant activation of the ERK and Notch pathways is critical for the ability of prostate cancer metastases to acquire osteoblast-like properties. Their results indicate that deregulation of Notch pathway may influence prostate cancer cells not only during the initial stages of the tumor in the prostate epithelium but also during the establishment of metastatic lesions.

More evidences for a functional relationship between androgen signals and Notch pathways were obtained by Martin et al. [88] by using a high throughput quantitative proteomic analysis of proteins secreted by $\mathrm{LNCaP}$ cells. This prostate cancer cell line was grown in a low protein-defined media under androgen-stimulated and androgenstarved conditions. Proteomic analysis of the media, verified by Western blot analysis, showed that androgens increased the levels of secreted Jagged1 and NOTCH2 extracellular domains. This observation reinforces the interesting possibility that hormone-mediated alterations in the expression of Notch pathway components may help to the integration of endocrine signals with cell-to-cell communication dependent on Notch receptors. In opposition to the previously discussed data from Nantermet et al. 
[73], which revealed changes in the expression of Notch components induced by androgen stimulation in the prostate suggesting an inhibition of Notch signaling, activation of androgen receptor in $\mathrm{LNCaP}$ cells correlates with an apparent increase in Notch signaling. This discrepancy may occur because both studies analyze different experimental models (changes induced in vivo in the rat prostate heterogeneous cell population versus in vitro effects on the established human LNCaP cell line) but it is tempting to speculate that they may reflect alterations in the mechanisms of crosstalk between the androgen signaling and the Notch pathway associated with the oncogenic phenotype. More research is needed to understand the molecular mechanisms that mediate the integration of these two signaling pathways in the prostate.

Santagata et al. have recently reported the first clinical breakthrough indicating that alterations in the expression of some components of Notch signaling are associated with prostate cancer in human patients [89]. They carried out an immunohistochemical analysis of Jagged1 protein expression in human prostatic specimens, revealing that Jagged 1 expression was increased significantly in clinically localized prostate cancer versus benign prostate tissue. Moreover, Jagged1 staining intensity was also increased in metastatic tumor as compared with either clinically localized prostate cancer or benign prostate tissue. Therefore, their data demonstrated an association between increased Jagged1 expression and progression from localized to metastatic prostate cancer (based on immunohistochemical analysis performed in tumor samples from 154 patients). Interestingly, high Jagged1 expression was significantly associated with recurrence, indicating that Jagged1 expression may be a useful marker to facilitate differentiating indolent from more aggressive prostate cancer. It is noteworthy to mention that in order to reach statistical significance they used only the maximum intensity values for each patient, reflecting the heterogeneous nature of prostate cancer. 
Thus, as they suggest, broad tissue sampling may be needed to maximize the possible predictive power of Jagged1 expression. In addition to the valuable clinical study, Santagata et al. also reported that the intracellular levels of Jagged1 protein in LNCaP cells increased after incubation with synthetic androgen analogs, confirming that Jagged1 expression increases in androgen-stimulated LNCaP cells [88]. Velasco et al. further demonstrated that Jagged1 is an androgen-regulated gene in LNCaP cells by using DNA microarray analysis [90].

Taken together, the results discussed above suggest that there is a direct impact of androgen-dependent signals on the modulation of Notch pathway and dysregulation of Jagged1 expression may play a role in prostate cancer cell growth and progression to metastatic disease. With the aim to elucidate the mechanistic role of Jagged1 in prostate cancer cell growth, Zhang et al. [91] examined the effect of small interfering RNAmediated knockdown of Jagged1 in human prostate cancer cell lines, and compared it with that of knockdown of NOTCH1 receptor. They monitored the expression of Notch ligands in PC-3, DU 145, LNCaP and C4-2B cells by real-time RT-PCR analysis and found that Jagged1 and Jagged2 expression were expressed at variable levels whereas DLL1 and DLL4 expression were negligible in all four cell lines. Downregulation of Jagged1 expression greatly decreased cell growth in those prostate cancer cell lines and NOTCH1 siRNA also induced growth inhibition, but to a lesser extent. These results add a new layer of complexity to the role of Notch in prostate cancer cells because the observed growth-inhibitory effects were independent of the cell line AR status, suggesting that Notch signaling impinges on androgen-independent cell growth regulatory mechanisms, in addition to its proposed role as a regulator of AR function. More in depth analysis of the mechanisms underlying cell growth inhibition in PC-3 cells depleted of endogenous Jagged1 or NOTCH1 showed that both Jagged1 and 
NOTCH1 siRNA induced S-phase arrest. In the case of Jagged1 knockdown, S-phase arrest was associated with reduced CDK2 kinase activity and increased expression of the cyclin-dependent kinase inhibitor p27(Kip1), suggesting that one of the mechanisms by which Notch signaling controls cell cycle is through regulation of CDK2 activity. The downregulation of CDK2 levels and the increase of p27 expression induced by Jagged1 siRNA treatment occur mainly at protein level and further studies will be required to uncover the detailed cellular pathways modulated by Notch responsible for these effects. The stronger growth inhibitory effects of Jagged1 knockdown compared to NOTCH1 knockdown suggest that Jagged1 itself could be important in prostate cancer cell growth independent of its role as a Notch ligand.

Belandia et al. [72] recently described further clinical evidence suggesting that alterations in Notch signaling may have a role in the aberrant hormonal responses observed in prostate cancer. Encouraged by the novel role for HEY1 as an AR repressor and the genetic data indicating that amplification of the chromosome region comprising HEY1 gene occurs in a large fraction of prostate cancers, and correlates with the aggressiveness of tumors [3], they examined HEY1 expression in a series of human primary prostate tumors by immunocytochemistry and compared it with benign prostatic hyperplasia (BPH) samples. This low-scale expression analysis (24 independent patients) uncovered a striking difference in the subcellular localization of HEY1 in patients with prostate cancer and BPH. The majority of BPH samples showed strong nuclear HEY1 staining whereas its expression was restricted to the cytoplasmic compartment of prostate carcinoma cells (in 8 out of 10 patients). More cancer samples need to be analyzed before these preliminary observations can be generalized, but, if HEY1 plays a role in the modulation of AR transcriptional activity in vivo in the normal prostate, its nuclear exclusion could contribute to the progression of prostate tumors by 
eliminating Notch-dependent modulation of AR-mediated signaling. In cancer cells HEY1 is excluded from the nuclei and therefore it would not repress AR action even when its expression is induced upon Notch activation. Moreover, if HEY1 was required for the repression of AR in the presence of antiandrogens, its cytoplasmic location may, at least in some cases, explain why cancer cells are resistant to antiandrogen treatment.

Meta-analysis of microarray datasets including tumors, as well as respective normal control tissue samples, has revealed that NOTCH1 gene and one of the downstream target genes, $H E Y 1$, are down-regulated significantly in prostate adenocarcinomas [79]. The expression levels of NOTCH1 in 51 prostate tumors were significantly lower than normal prostate samples and the mean level of HEY1 expression was also significantly lower in 93 prostate adenocarcinomas than both normal and tumor-adjacent normal tissues. These observations reinforce the idea that NOTCH1 and HEY1 may be important in prostate tumorigenesis.

Finally, additional evidence for dysregulation of Notch1 expression in prostate cancer was revealed by expression analysis performed during prostate tumor development in the LADY transgenic mouse model [92]. These mice express the large $\mathrm{T}$ antigen gene, containing a deletion mutation that removes expression of small $\mathrm{t}$ antigen, under the control of the prostate luminal cell-specific rat probasin promoter [93]. As compared with the TRAMP mouse model, tumor progression is less aggressive in LADY transgenic mice, but they develop multifocal low-grade PIN that progresses to high-grade PIN and early invasive carcinoma with neuroendocrine characteristics but no metastasis. NOTCH1 expression increased significantly in the six-week developing tumor, but not in the established 16-week tumor [92]. These observations suggest that NOTCH1 has an early role in the regulation of prostate epithelial cell proliferation and differentiation prior to the appearance of histological changes. Increased NOTCH1 
expression was also found in prostate tumors from TRAMP mouse models [58]. However, in this model of prostate carcinogenesis, high NOTCH1 expression is maintained even in metastasized tumor cells. This discrepancy between both models may reflect the different mechanisms responsible for the oncogenic development and/or differences in the strain background between the TRAMP and the LADY models. In addition, conversely to the up-regulation of Notch1 expression observed in these SV40 oncogene-derived mouse models of prostate carcinogenesis, the meta-analysis of human prostate adenocarcinoma mentioned above found downregulation of NOTCH1 expression in human cancer samples [79]. We do not know yet whether these apparently conflicting results are caused by a specific characteristic of SV40-derived tumors in the mouse models but, independently of the direction of the changes in NOTCH1 expression, those studies indicate that abnormalities in Notch signaling may be critical during the development of prostate cancer.

\section{NOTCH SIGNALING: A POTENTIAL THERAPEUTIC TARGET IN}

\section{PROSTATE CANCER}

Although our knowledge of the biological role of Notch signaling during normal prostate development and homeostasis is still preliminary, it is evident that Notchmediated signals play an important role in the regulation of prostate cell differentiation and proliferation. In addition, a few clinical and experimental evidences point out that, in many cases, alterations in the expression of several components of the Notch pathway may be associated with the origin or progression of prostate cancer, both in mouse models and human primary tumors. Therefore, Notch signaling emerges as a novel potential target to design strategies for the treatment of prostate cancer. Inhibition of Notch signaling is a therapeutic approach that has been extensively investigated 
during recent years as a novel alternative for the treatment of several malignancies in which activation of Notch signals has an oncogenic role. These include T-ALL, breast, cervical, endometrial, renal, head and neck squamous cell, pancreatic and lung carcinomas and also gliomas, pleural mesotheliomas, melanomas, several types of lymphomas, and multiple myeloma (reviewed in [52, 94]). All the experimental evidence described in the previous sections indicates that Notch pathway plays a critical role in the regulation of prostate epithelial cell fate specification, differentiation and proliferation. However, in opposition to the clear oncogenic role of activated Notch signaling in other types of cancer, the role of Notch signals during prostate tumorigenesis is not yet completely understood, and it may act as a tumor suppressor or an oncogenic agent depending on the stage of the disease and/or the type of prostate tumor. We have discussed some studies that suggest an oncogenic role for Notch signaling in the prostate. For instance, in TRAMP and LADY mice transgenic models, NOTCH1 expression is elevated in malignant prostatic epithelial cells [58, 92]. Nevertheless, while elevated NOTCH1 expression is maintained in metastasized prostate tumor cells in TRAMP mice, NOTCH1 expression seem to be only transiently expressed in LADY mice, because the increase in NOTCH1 expression was not found in established tumors. The loss of aberrant increased NOTCH expression in established tumors could reflect the inability of LADY prostate tumors to metastasize, because elevated NOTCH1 expression was also described in osteoblastic skeletal prostate metastatic cell lines [85]. Abnormal high expression of other component of the Notch pathway, the ligand Jagged1, is associated with prostate cancer metastasis and recurrence in humans [89], but we do not know yet whether high Jagged1 expression correlates with excessive activation of Notch signaling in those tumors. On the other hand, a meta-analysis of microarray data described a significant downregulation of 
NOTCH1 gene in human prostate adenocarcinomas [79]. This type of analysis needs further experimental validation, and no significant changes in the expression of other Notch pathway genes were found, but this downregulation of NOTCH1 gene may indicate a selection in prostate tumors for cells with reduced NOTCH1-dependent signaling. Contradictory results have been also obtained when studying the role of Notch signaling in the regulation of prostate cancer cell proliferation in vitro. Overexpression of a constitutively active form of NOTCH1 inhibited the proliferation of various prostate cancer cells, including DU 145, LNCaP and PC-3 cell lines [58]. In contrast, siRNA-mediated downregulation of NOTCH1 or Jagged1 also induces cell growth inhibition and $\mathrm{S}$ phase arrest in the same prostate cancer cell lines [91], and in vitro studies with GSIs demonstrated that reduction of Notch signaling induces a moderate inhibition of proliferation in LNCaP and DU-145 cells [64]. Even though all these studies point to an important role for Notch signaling in the regulation of prostate cancer cell proliferation, the complexity of the biological role of Notch signals in the prostate cell make it difficult to decipher whether Notch acts an oncogen or a tumor suppressor. In addition, these effects occur both in AR dependent and AR-independent prostate cancer cell lines, suggesting that besides the previously described crosstalk between AR-dependent and Notch signals, Notch also regulates prostate cells by means of crosstalk with androgen-independent transduction pathways.

These seemingly conflicting results surely derive from our incomplete knowledge of the role of Notch signaling in the regulation of prostate cell biology. More research is needed to gain the information that may help us to understand how alterations in the normal function of Notch signals are implicated in the origin and progression of prostate cancer. A thorough expression analysis for all Notch receptors, ligands and modulators in prostate epithelial cells is still lacking, and more research with prostate 
cancer mice models will undoubtedly help us to understand the role of Notch signals in prostate cancer. These animal models will be invaluable to test how modulation of Notch activity can be used as a therapeutic tool in prostate cancer. A number of strategies for inhibition of Notch signaling have been designed, including antisense Notch treatments, monoclonal antibodies, RNA interference, soluble decoy Notch inhibitors that sequester Notch ligands and dominant-negative peptides derived from MAML1 (reviewed in [52]). Currently, the most advanced strategy for blocking Notch signaling is to suppress the proteolytic step that leads to the release of the activated intracellular domain of Notch receptors [81]. This step is catalyzed by the gammasecretase, a large integral membrane protease complex composed of a catalytic subunit (presenilin-1 or presenilin-2) and three accessory subunits (Pen-2, Aph1 and nicastrin $[36,95,96])$. This enzyme is also responsible for the proteolytic step that releases the amyloid $\beta$-peptide, the precursor of amyloid plaques found in the brain of Alzheimer's disease. For that reason, over the past years, a great variety of small molecules of pharmaceutical utility have been designed, and already tested in animal models and clinical trials, able to inhibit gamma-secretase activity. This preceding research has speeded up the initiation of phase 1 clinical trials designed to evaluate the effectiveness of one GSI (MK-0752) for the treatment of $\mathrm{T}_{-\mathrm{ALL}^{1}}$ and breast cancer ${ }^{2}$. Due to the highly variable nature of prostate cancer tumors we cannot predict the fraction of prostate tumors that may be suitable for treatment with GSIs, or at what stage of the disease inhibition of Notch signaling may be an useful therapeutic approach. In vitro treatment with GSIs seems to increase normal prostate cell proliferation in developing prostate grown in culture [79]. However, a similar treatment with GSIs of primary cultures of human prostatic transit-amplifying cells established from adult prostate induces cell death and, also, a moderate inhibition of cell proliferation in some prostate 
cancer cell lines [64]. These preliminary studies suggest that active Notch signaling could be associated with proliferating prostate epithelial cells, implying that inhibition of Notch signaling may be a potential treatment aimed to inhibit prostate tumor growth.

There are several concerns regarding the clinical use of GSIs that should be kept in mind: the processing of other gamma-secretase substrates than Notch receptors could be affected, the inhibitors could target different types of proteases, and the Notch pathway has pleiotropic effects in many different tissues. Thus, toxic side effects may sometimes be associated with the clinical use of these compounds. Nonetheless, extensive ongoing research in this field, both at pre-clinical stage and in clinical trials, is helping to the development of novel classes of GSIs which may help to find a better specific treatment for different diseases related to gamma-secretase activity.

\section{CONCLUDING REMARKS}

Although there are still too many questions unanswered, and the available fragmentary information does not allow us to predict how widely useful inhibition of Notch signaling will be to treat prostate cancer patients, the high prevalence and mortality rates of these type of tumors have to drive us to keep working towards understanding the role of Notch in prostate cell biology. The findings discussed above indicate that expression analysis of components of the Notch pathway in prostate tumors may not only help to design novel future therapeutic strategies, but also to be

used as novel predictive markers useful to manage prostate cancer. Currently, several therapies are available for prostate cancer treatment, including radiation therapy, chemotherapy, surgery and hormonal therapy. Combined treatments usually work best for prostate cancer therapy and the addition to the list of possible treatments of novel drugs capable of inhibiting prostate cancer cell proliferation could contribute to the 
design of improved therapeutic protocols. Furthermore, an abnormal crosstalk between Notch and androgen-dependent signaling in prostate cancer cells may be one of the possible causes for the failure of hormone therapy in some hormone-refractory prostate tumors (Fig. (1)). If that hypothesis is true, the combined use of drugs targeting Notch signals with anti-androgens may help to obtain better results and overcome the resistance to hormonal therapy. An individualized tumor analysis will surely be needed to predict the feasibility of the use of inhibition of Notch signaling as an alternative, or complementary treatment, as part of a multifaceted attack against the prostate cancer cells. The discovery of novel strategies to target hormone-refractory prostate cancer is one of the fundamental challenges for researchers in the field and the elucidation of the biological role of Notch signaling in prostate cell physiology may help to develop combination therapies more effective for the treatment of prostate cancer. 


\section{ACKNOWLEDGEMENTS}

Our laboratories were supported by the Ministerio de Educación y Ciencia (grants SAF2004-02549 and SAF2007-62642), the Fundación de Investigación Médica Mutua Madrileña, the Fondo de Investigaciones Sanitarias (grant RD06/0020/0036), the European Grant CRESCENDO (FP-018652), Cancer Research UK and The Prostate Cancer Charity.

\begin{tabular}{|c|c|}
\hline \multicolumn{2}{|c|}{ ABBREVIATIONS } \\
\hline ADAM & $=\mathrm{A}$ disintegrin and metalloprotease \\
\hline AIB1 & $=$ Amplified in breast cancer 1 \\
\hline AIPC & $=$ Androgen independent prostate cancer \\
\hline AR & $=$ Androgen receptor \\
\hline $\mathrm{BPH}$ & $=$ Benign prostate hyperplasia \\
\hline CDK2 & $=$ Cyclin-dependent kinase 2 \\
\hline CSL & $=\mathrm{CBF}-1$, suppressor of hairless and LAG-1 \\
\hline $\mathrm{CtBP}$ & $=\mathrm{C}$-terminal Binding Protein \\
\hline DLL1 & $=$ Delta-like 1 \\
\hline DLL3 & $=$ Delta-like 3 \\
\hline DLL4 & $=$ Delta-like 4 \\
\hline ERK & $=$ Extracellular signal-regulated kinase \\
\hline GFP & $=$ Green fluorescent protein \\
\hline GSI & $=$ Gamma-secretase inhibitor \\
\hline HEY 1 & $=$ Hairy/Enhancer-of-split related with YRPW motif 1 \\
\hline MAML1 & $=$ Mastermind-like 1 \\
\hline MAPK & $=$ Mitogen activated protein kinase \\
\hline
\end{tabular}




\begin{tabular}{|c|c|}
\hline NCoA1 & $=$ Nuclear receptor coactivator 1 \\
\hline $\mathrm{NCoA} 2$ & $=$ Nuclear receptor coactivator 2 \\
\hline $\mathrm{NCoA} 3$ & $=$ Nuclear receptor coactivator 3 \\
\hline $\mathrm{NCoR}$ & $=$ Nuclear receptor corepressor \\
\hline NICD & $=$ Notch intracellular domain \\
\hline NR & $=$ Nuclear receptor \\
\hline $\mathrm{PC}$ & $=$ Prostate cancer \\
\hline PIN & $=$ Prostatic intraepithelial neoplasia \\
\hline PSCA & $=$ Prostate stem cell antigen \\
\hline SHARP & $=\mathrm{SMRT} / \mathrm{HDAC} 1$-associated repressor protein \\
\hline $\mathrm{SRC1}$ & $=$ Steroid Receptor Coactivator 1 \\
\hline SV40 & $=$ Simian virus 40 \\
\hline T-ALL & $=\mathrm{T}$-cell acute lymphoblastic leukemia \\
\hline TIF2 & $=$ Transcriptional intermediary factor 2 \\
\hline TRAMP & $=$ Transgenic adenocarcinoma of mouse prostate \\
\hline
\end{tabular}

\section{FOOTNOTES}

${ }^{1}$ Deangelo, D. J.; Stone, R. M.; Silverman, L. B.; Stock, W.; Attar, E. C.; Fearen, I.; Dallob, A.; Matthews, C. ; Stone, J.; Freedman, S. J.; Aster, J. A phase I clinical trial of the notch inhibitor MK-0752 in patients with T-cell acute lymphoblastic leukemia/lymphoma (T-ALL) and other leukemias. J. Clin. Oncol. (Meeting abstracts) 2006, 24, 6585 .

${ }^{2}$ Krop, I. E.; Kosh, M.; Fearen, I.; Savoie, J.; Dallob, A.; Matthews, C., Stone, J.; Winer, E.; Freedman, S. J.; Lorusso. P. Phase I pharmacokinetic (PK), and pharmacodynamic (PD) trial of the novel oral Notch inhibitor MK-0752 in patients (pts) 
with advanced breast cancer (BC) and other solid tumors. J. Clin. Oncol. (Meeting abstracts) 2006, 24, 10574.

\section{REFERENCES}

[1] Marker, P. C.; Donjacour, A. A.; Dahiya, R.; Cunha, G. R. Hormonal, cellular, and molecular control of prostatic development. Dev. Biol. 2003, 253, 165-174.

[2] Abate-Shen, C.; Shen, M. M. Molecular genetics of prostate cancer. Genes Dev. 2000, 14, 2410-2434.

[3] DeMarzo, A. M.; Nelson, W. G.; Isaacs, W. B.; Epstein, J. I. Pathological and molecular aspects of prostate cancer. Lancet 2003, 361, 955-964.

[4] Deutsch, E.; Maggiorella, L.; Eschwege, P.; Bourhis, J.; Soria, J. C.; Abdulkarim, B. Environmental, genetic, and molecular features of prostate cancer. Lancet Oncol. 2004, 5, 303-313.

[5] Jemal, A.; Siegel, R.; Ward, E.; Murray, T.; Xu, J.; Thun, M. J. Cancer statistics, 2007. CA Cancer J. Clin. 2007, 57, 43-66.

[6] Hayward, S. W.; Grossfeld, G. D.; Tlsty, T. D.; Cunha, G. R. Genetic and epigenetic influences in prostatic carcinogenesis (review). Int. J. Oncol. 1998, $13,35-47$.

[7] Culig, Z.; Steiner, H.; Bartsch, G.; Hobisch, A. Mechanisms of endocrine therapy-responsive and -unresponsive prostate tumours. Endocr. Relat. Cancer 2005, 12, 229-244.

[8] Heinlein, C. A.; Chang, C. Androgen receptor in prostate cancer. Endocr. Rev. 2004, 25, 276-308. 
[9] Long, R. M.; Morrissey, C.; Fitzpatrick, J. M.; Watson, R. W. Prostate epithelial cell differentiation and its relevance to the understanding of prostate cancer therapies. Clin. Sci. (Lond.) 2005, 108, 1-11.

[10] Peehl, D. M. Primary cell cultures as models of prostate cancer development. Endocr. Relat. Cancer 2005, 12, 19-47.

[11] Uzgare, A. R.; Xu, Y.; Isaacs, J. T. In vitro culturing and characteristics of transit amplifying epithelial cells from human prostate tissue. J. Cell. Biochem. 2004, 91, 196-205.

[12] English, H. F.; Santen, R. J.; Isaacs, J. T. Response of glandular versus basal rat ventral prostatic epithelial cells to androgen withdrawal and replacement. Prostate 1987, 11, 229-242.

[13] Hudson, D. L. Epithelial stem cells in human prostate growth and disease. Prostate Cancer Prostatic Dis. 2004, 7, 188-194.

[14] Lawson, D. A.; Witte, O. N. Stem cells in prostate cancer initiation and progression. J. Clin. Invest. 2007, 117, 2044-2050.

[15] Mangelsdorf, D. J.; Thummel, C.; Beato, M.; Herrlich, P.; Schutz, G.; Umesono, K.; Blumberg, B.; Kastner, P.; Mark, M.; Chambon, P.; Evans, R. M. The nuclear receptor superfamily: the second decade. Cell 1995, 83, 835-839.

[16] Denmeade, S. R.; Lin, X. S.; Isaacs, J. T. Role of programmed (apoptotic) cell death during the progression and therapy for prostate cancer. Prostate 1996, 28, 251-265.

[17] Huggins, C.; Hodges, C. V. Studies on prostatic cancer. I. The effect of castration, of estrogen and androgen injection on serum phosphatases in metastatic carcinoma of the prostate. CA Cancer J. Clin. 1972, 22, 232-240. 
[18] Pienta, K. J.; Bradley, D. Mechanisms underlying the development of androgenindependent prostate cancer. Clin. Cancer Res. 2006, 12, 1665-1671.

[19] Rau, K. M.; Kang, H. Y.; Cha, T. L.; Miller, S. A.; Hung, M. C. The mechanisms and managements of hormone-therapy resistance in breast and prostate cancers. Endocr. Relat. Cancer 2005, 12, 511-532.

[20] Taplin, M. E. Drug insight: role of the androgen receptor in the development and progression of prostate cancer. Nat. Clin. Pract. Oncol. 2007, 4, 236-244.

[21] Kaarbo, M.; Klokk, T. I.; Saatcioglu, F. Androgen signaling and its interactions with other signaling pathways in prostate cancer. Bioessays 2007, 29, 12271238.

[22] Artavanis-Tsakonas, S.; Rand, M. D.; Lake, R. J. Notch signaling: cell fate control and signal integration in development. Science 1999, 284, 770-776.

[23] Del Amo, F. F.; Smith, D. E.; Swiatek, P. J.; Gendron-Maguire, M.; Greenspan, R. J.; McMahon, A. P.; Gridley, T. Expression pattern of Motch, a mouse homolog of Drosophila Notch, suggests an important role in early postimplantation mouse development. Development 1992, 115, 737-744.

[24] Lardelli, M.; Dahlstrand, J.; Lendahl, U. The novel Notch homologue mouse Notch 3 lacks specific epidermal growth factor-repeats and is expressed in proliferating neuroepithelium. Mech. Dev. 1994, 46, 123-136.

[25] Lardelli, M.; Lendahl, U. Motch A and motch B--two mouse Notch homologues coexpressed in a wide variety of tissues. Exp. Cell Res. 1993, 204, 364-372.

[26] Uyttendaele, H.; Marazzi, G.; Wu, G.; Yan, Q.; Sassoon, D.; Kitajewski, J. Notch4/int-3, a mammary proto-oncogene, is an endothelial cell-specific mammalian Notch gene. Development 1996, 122, 2251-2259. 
[27] Weinmaster, G.; Roberts, V. J.; Lemke, G. Notch2: a second mammalian Notch gene. Development 1992, 116, 931-941.

[28] Bettenhausen, B.; Hrabe de Angelis, M.; Simon, D.; Guenet, J. L.; Gossler, A. Transient and restricted expression during mouse embryogenesis of D111, a murine gene closely related to Drosophila Delta. Development 1995, 121, 24072418.

[29] Dunwoodie, S. L.; Henrique, D.; Harrison, S. M.; Beddington, R. S. Mouse D113: a novel divergent Delta gene which may complement the function of other Delta homologues during early pattern formation in the mouse embryo. Development 1997, 124, 3065-3076.

[30] Shutter, J. R.; Scully, S.; Fan, W.; Richards, W. G.; Kitajewski, J.; Deblandre, G. A.; Kintner, C. R.; Stark, K. L. D114, a novel Notch ligand expressed in arterial endothelium. Genes Dev. 2000, 14, 1313-1318.

[31] Lindsell, C. E.; Shawber, C. J.; Boulter, J.; Weinmaster, G. Jagged: a mammalian ligand that activates Notch1. Cell 1995, 80, 909-917.

[32] Shawber, C.; Boulter, J.; Lindsell, C. E.; Weinmaster, G. Jagged2: a serrate-like gene expressed during rat embryogenesis. Dev. Biol. 1996, 180, 370-376.

[33] Fehon, R. G.; Kooh, P. J.; Rebay, I.; Regan, C. L.; Xu, T.; Muskavitch, M. A.; Artavanis-Tsakonas, S. Molecular interactions between the protein products of the neurogenic loci Notch and Delta, two EGF-homologous genes in Drosophila. Cell 1990, 61, 523-534.

[34] Rebay, I.; Fleming, R. J.; Fehon, R. G.; Cherbas, L.; Cherbas, P.; ArtavanisTsakonas, S. Specific EGF repeats of Notch mediate interactions with Delta and Serrate: implications for Notch as a multifunctional receptor. Cell 1991, 67, 687699. 
[35] Mumm, J. S.; Schroeter, E. H.; Saxena, M. T.; Griesemer, A.; Tian, X.; Pan, D. J.; Ray, W. J.; Kopan, R. A ligand-induced extracellular cleavage regulates gamma-secretase-like proteolytic activation of Notch1. Mol. Cell 2000, 5, 197206.

[36] Fortini, M. E. Gamma-secretase-mediated proteolysis in cell-surface-receptor signalling. Nat. Rev. Mol. Cell Biol. 2002, 3, 673-684.

[37] Kao, H. Y.; Ordentlich, P.; Koyano-Nakagawa, N.; Tang, Z.; Downes, M.; Kintner, C. R.; Evans, R. M.; Kadesch, T. A histone deacetylase corepressor complex regulates the Notch signal transduction pathway. Genes Dev. 1998, 12, 2269-2277.

[38] Oswald, F.; Winkler, M.; Cao, Y.; Astrahantseff, K.; Bourteele, S.; Knochel, W.; Borggrefe, T. RBP-Jkappa/SHARP recruits CtIP/CtBP corepressors to silence Notch target genes. Mol. Cell. Biol. 2005, 25, 10379-10390.

[39] Kurooka, H.; Honjo, T. Functional interaction between the mouse notch1 intracellular region and histone acetyltransferases PCAF and GCN5. J. Biol. Chem. 2000, 275, 17211-17220.

[40] Wu, L.; Aster, J. C.; Blacklow, S. C.; Lake, R.; Artavanis-Tsakonas, S.; Griffin, J. D. MAML1, a human homologue of Drosophila mastermind, is a transcriptional co-activator for NOTCH receptors. Nat. Genet. 2000, 26, 484489.

[41] Davis, R. L.; Turner, D. L. Vertebrate hairy and Enhancer of split related proteins: transcriptional repressors regulating cellular differentiation and embryonic patterning. Oncogene 2001, 20, 8342-8357. 
[42] Fischer, A.; Gessler, M. Delta-Notch--and then? Protein interactions and proposed modes of repression by Hes and Hey bHLH factors. Nucleic Acids Res. 2007, 35, 4583-4596.

[43] Iso, T.; Kedes, L.; Hamamori, Y. HES and HERP families: multiple effectors of the Notch signaling pathway. J. Cell. Physiol. 2003, 194, 237-255.

[44] Bolos, V.; Grego-Bessa, J.; de la Pompa, J. L. Notch signaling in development and cancer. Endocr. Rev. 2007, 28, 339-363.

[45] Miele, L.; Osborne, B. Arbiter of differentiation and death: Notch signaling meets apoptosis. J. Cell. Physiol. 1999, 181, 393-409.

[46] Ellisen, L. W.; Bird, J.; West, D. C.; Soreng, A. L.; Reynolds, T. C.; Smith, S. D.; Sklar, J. TAN-1, the human homolog of the Drosophila notch gene, is broken by chromosomal translocations in T lymphoblastic neoplasms. Cell 1991, 66, 649-661.

[47] Weng, A. P.; Ferrando, A. A.; Lee, W.; Morris, J. P. t.; Silverman, L. B.; Sanchez-Irizarry, C.; Blacklow, S. C.; Look, A. T.; Aster, J. C. Activating mutations of NOTCH1 in human T cell acute lymphoblastic leukemia. Science 2004, 306, 269-271.

[48] Grabher, C.; von Boehmer, H.; Look, A. T. Notch 1 activation in the molecular pathogenesis of T-cell acute lymphoblastic leukaemia. Nat. Rev. Cancer 2006, 6, 347-359.

[49] Jhappan, C.; Gallahan, D.; Stahle, C.; Chu, E.; Smith, G. H.; Merlino, G.; Callahan, R. Expression of an activated Notch-related int-3 transgene interferes with cell differentiation and induces neoplastic transformation in mammary and salivary glands. Genes Dev. 1992, 6, 345-355. 
[50] Weijzen, S.; Rizzo, P.; Braid, M.; Vaishnav, R.; Jonkheer, S. M.; Zlobin, A.; Osborne, B. A.; Gottipati, S.; Aster, J. C.; Hahn, W. C.; Rudolf, M.; Siziopikou, K.; Kast, W. M.; Miele, L. Activation of Notch-1 signaling maintains the neoplastic phenotype in human Ras-transformed cells. Nat. Med. 2002, 8, 979986.

[51] Capobianco, A. J.; Zagouras, P.; Blaumueller, C. M.; Artavanis-Tsakonas, S.; Bishop, J. M. Neoplastic transformation by truncated alleles of human NOTCH1/TAN1 and NOTCH2. Mol. Cell. Biol. 1997, 17, 6265-6273.

[52] Miele, L.; Miao, H.; Nickoloff, B. J. NOTCH signaling as a novel cancer therapeutic target. Curr. Cancer Drug Targets 2006, 6, 313-323.

[53] Radtke, F.; Raj, K. The role of Notch in tumorigenesis: oncogene or tumour suppressor? Nat. Rev. Cancer 2003, 3, 756-767.

[54] Roy, M.; Pear, W. S.; Aster, J. C. The multifaceted role of Notch in cancer. Curr. Opin. Genet. Dev. 2007, 17, 52-59.

[55] Rangarajan, A.; Talora, C.; Okuyama, R.; Nicolas, M.; Mammucari, C.; Oh, H.; Aster, J. C.; Krishna, S.; Metzger, D.; Chambon, P.; Miele, L.; Aguet, M.; Radtke, F.; Dotto, G. P. Notch signaling is a direct determinant of keratinocyte growth arrest and entry into differentiation. Embo J. 2001, 20, 3427-3436.

[56] Nicolas, M.; Wolfer, A.; Raj, K.; Kummer, J. A.; Mill, P.; van Noort, M.; Hui, C. C.; Clevers, H.; Dotto, G. P.; Radtke, F. Notch1 functions as a tumor suppressor in mouse skin. Nat. Genet. 2003, 33, 416-421.

[57] Proweller, A.; Tu, L.; Lepore, J. J.; Cheng, L.; Lu, M. M.; Seykora, J.; Millar, S. E.; Pear, W. S.; Parmacek, M. S. Impaired notch signaling promotes de novo squamous cell carcinoma formation. Cancer Res. 2006, 66, 7438-7444. 
[58] Shou, J.; Ross, S.; Koeppen, H.; de Sauvage, F. J.; Gao, W. Q. Dynamics of notch expression during murine prostate development and tumorigenesis. Cancer Res. 2001, 61, 7291-7297.

[59] Chung, L. W.; Chang, S. M.; Bell, C.; Zhau, H. E.; Ro, J. Y.; von Eschenbach, A. C. Co-inoculation of tumorigenic rat prostate mesenchymal cells with nontumorigenic epithelial cells results in the development of carcinosarcoma in syngeneic and athymic animals. Int. J. Cancer 1989, 43, 1179-1187.

[60] Hayashi, N.; Cunha, G. R.; Wong, Y. C. Influence of male genital tract mesenchymes on differentiation of Dunning prostatic adenocarcinoma. Cancer Res. 1990, 50, 4747-4754.

[61] Morton, R. A.; Ewing, C. M.; Nagafuchi, A.; Tsukita, S.; Isaacs, W. B. Reduction of E-cadherin levels and deletion of the alpha-catenin gene in human prostate cancer cells. Cancer Res. 1993, 53, 3585-3590.

[62] Lewis, A. K.; Frantz, G. D.; Carpenter, D. A.; de Sauvage, F. J.; Gao, W. Q. Distinct expression patterns of notch family receptors and ligands during development of the mammalian inner ear. Mech. Dev. 1998, 78, 159-163.

[63] Tran, C. P.; Lin, C.; Yamashiro, J.; Reiter, R. E. Prostate stem cell antigen is a marker of late intermediate prostate epithelial cells. Mol. Cancer Res. 2002, 1, 113-121.

[64] Dalrymple, S.; Antony, L.; Xu, Y.; Uzgare, A. R.; Arnold, J. T.; Savaugeot, J.; Sokoll, L. J.; De Marzo, A. M.; Isaacs, J. T. Role of notch-1 and E-cadherin in the differential response to calcium in culturing normal versus malignant prostate cells. Cancer Res. 2005, 65, 9269-9279. 
[65] Litvinov, I. V.; Vander Griend, D. J.; Xu, Y.; Antony, L.; Dalrymple, S. L.; Isaacs, J. T. Low-calcium serum-free defined medium selects for growth of normal prostatic epithelial stem cells. Cancer Res. 2006, 66, 8598-8607.

[66] van Bokhoven, A.; Varella-Garcia, M.; Korch, C.; Johannes, W. U.; Smith, E. E.; Miller, H. L.; Nordeen, S. K.; Miller, G. J.; Lucia, M. S. Molecular characterization of human prostate carcinoma cell lines. Prostate 2003, 57, 205225.

[67] Garraway, L. A.; Lin, D.; Signoretti, S.; Waltregny, D.; Dilks, J.; Bhattacharya, N.; Loda, M. Intermediate basal cells of the prostate: in vitro and in vivo characterization. Prostate 2003, 55, 206-218.

[68] Rand, M. D.; Grimm, L. M.; Artavanis-Tsakonas, S.; Patriub, V.; Blacklow, S. C.; Sklar, J.; Aster, J. C. Calcium depletion dissociates and activates heterodimeric notch receptors. Mol. Cell. Biol. 2000, 20, 1825-1835.

[69] Leo, C.; Chen, J. D. The SRC family of nuclear receptor coactivators. Gene 2000, $245,1-11$.

[70] Xu, J.; Li, Q. Review of the in vivo functions of the p160 steroid receptor coactivator family. Mol. Endocrinol. 2003, 17, 1681-1692.

[71] Belandia, B.; Orford, R. L.; Hurst, H. C.; Parker, M. G. Targeting of SWI/SNF chromatin remodelling complexes to estrogen-responsive genes. Embo J. 2002, 21, 4094-4103.

[72] Belandia, B.; Powell, S. M.; Garcia-Pedrero, J. M.; Walker, M. M.; Bevan, C. L.; Parker, M. G. Hey1, a mediator of notch signaling, is an androgen receptor corepressor. Mol. Cell. Biol. 2005, 25, 1425-1436.

[73] Nantermet, P. V.; Xu, J.; Yu, Y.; Hodor, P.; Holder, D.; Adamski, S.; Gentile, M. A.; Kimmel, D. B.; Harada, S. I.; Gerhold, D.; Freedman, L. P.; Ray, W. J. 
Identification of genetic pathways activated by the androgen receptor during the induction of proliferation in the ventral prostate gland. J. Biol. Chem. 2004, 279, $1310-1322$.

[74] Donoviel, D. B.; Donoviel, M. S.; Fan, E.; Hadjantonakis, A.; Bernstein, A. Cloning and characterization of Sel-11, a murine homolog of the C. elegans sel-1 gene. Mech. Dev. 1998, 78, 203-207.

[75] Elagib, K. E.; Xiao, M.; Hussaini, I. M.; Delehanty, L. L.; Palmer, L. A.; Racke, F. K.; Birrer, M. J.; Shanmugasundaram, G.; McDevitt, M. A.; Goldfarb, A. N. Jun blockade of erythropoiesis: role for repression of GATA-1 by HERP2. Mol. Cell. Biol. 2004, 24, 7779-7794.

[76] Fischer, A.; Klattig, J.; Kneitz, B.; Diez, H.; Maier, M.; Holtmann, B.; Englert, C.; Gessler, M. Hey basic helix-loop-helix transcription factors are repressors of GATA4 and GATA6 and restrict expression of the GATA target gene ANF in fetal hearts. Mol. Cell. Biol. 2005, 25, 8960-8970.

[77] Wang, X. D.; Shou, J.; Wong, P.; French, D. M.; Gao, W. Q. Notch1-expressing cells are indispensable for prostatic branching morphogenesis during development and re-growth following castration and androgen replacement. $J$. Biol. Chem. 2004, 279, 24733-24744.

[78] Belandia, B.; Parker, M. G. Nuclear receptor regulation gears up another Notch. Nucl. Recept. Signal. 2006, 4, e001.

[79] Wang, X. D.; Leow, C. C.; Zha, J.; Tang, Z.; Modrusan, Z.; Radtke, F.; Aguet, M.; de Sauvage, F. J.; Gao, W. Q. Notch signaling is required for normal prostatic epithelial cell proliferation and differentiation. Dev. Biol. 2006, 290, $66-80$. 
[80] Carlson, M. E.; Conboy, I. M. Regulating the Notch pathway in embryonic, adult and old stem cells. Curr. Opin. Pharmacol. 2007, 7, 303-309.

[81] Shih Ie, M.; Wang, T. L. Notch signaling, gamma-secretase inhibitors, and cancer therapy. Cancer Res. 2007, 67, 1879-1882.

[82] Radtke, F.; Wilson, A.; Stark, G.; Bauer, M.; van Meerwijk, J.; MacDonald, H. R.; Aguet, M. Deficient $\mathrm{T}$ cell fate specification in mice with an induced inactivation of Notch1. Immunity 1999, 10, 547-558.

[83] Greenberg, N. M.; DeMayo, F.; Finegold, M. J.; Medina, D.; Tilley, W. D.; Aspinall, J. O.; Cunha, G. R.; Donjacour, A. A.; Matusik, R. J.; Rosen, J. M. Prostate cancer in a transgenic mouse. Proc. Natl. Acad. Sci. U S A 1995, 92, 3439-3443.

[84] Scorey, N.; Fraser, S. P.; Patel, P.; Pridgeon, C.; Dallman, M. J.; Djamgoz, M. B. Notch signalling and voltage-gated $\mathrm{Na}+$ channel activity in human prostate cancer cells: independent modulation of in vitro motility. Prostate Cancer Prostatic Dis. 2006, 9, 399-406.

[85] Zayzafoon, M.; Abdulkadir, S. A.; McDonald, J. M. Notch signaling and ERK activation are Important for the osteomimetic properties of prostate cancer bone metastatic cell lines. J. Biol. Chem. 2004, 279, 3662-3670.

[86] Koeneman, K. S.; Yeung, F.; Chung, L. W. Osteomimetic properties of prostate cancer cells: a hypothesis supporting the predilection of prostate cancer metastasis and growth in the bone environment. Prostate 1999, 39, 246-261.

[87] Tezuka, K.; Yasuda, M.; Watanabe, N.; Morimura, N.; Kuroda, K.; Miyatani, S.; Hozumi, N. Stimulation of osteoblastic cell differentiation by Notch. J. Bone Miner. Res. 2002, 17, 231-239. 
[88] Martin, D. B.; Gifford, D. R.; Wright, M. E.; Keller, A.; Yi, E.; Goodlett, D. R.; Aebersold, R.; Nelson, P. S. Quantitative proteomic analysis of proteins released by neoplastic prostate epithelium. Cancer Res. 2004, 64, 347-355.

[89] Santagata, S.; Demichelis, F.; Riva, A.; Varambally, S.; Hofer, M. D.; Kutok, J. L.; Kim, R.; Tang, J.; Montie, J. E.; Chinnaiyan, A. M.; Rubin, M. A.; Aster, J. C. JAGGED1 expression is associated with prostate cancer metastasis and recurrence. Cancer Res. 2004, 64, 6854-6857.

[90] Velasco, A. M.; Gillis, K. A.; Li, Y.; Brown, E. L.; Sadler, T. M.; Achilleos, M.; Greenberger, L. M.; Frost, P.; Bai, W.; Zhang, Y. Identification and validation of novel androgen-regulated genes in prostate cancer. Endocrinology 2004, 145, 3913-3924.

[91] Zhang, Y.; Wang, Z.; Ahmed, F.; Banerjee, S.; Li, Y.; Sarkar, F. H. Downregulation of Jagged-1 induces cell growth inhibition and $\mathrm{S}$ phase arrest in prostate cancer cells. Int. J. Cancer 2006, 119, 2071-2077.

[92] Gipp, J.; Gu, G.; Crylen, C.; Kasper, S.; Bushman, W. Hedgehog pathway activity in the LADY prostate tumor model. Mol. Cancer 2007, 6, 19.

[93] Kasper, S.; Sheppard, P. C.; Yan, Y.; Pettigrew, N.; Borowsky, A. D.; Prins, G. S.; Dodd, J. G.; Duckworth, M. L.; Matusik, R. J. Development, progression, and androgen-dependence of prostate tumors in probasin-large $\mathrm{T}$ antigen transgenic mice: a model for prostate cancer. Lab. Invest. 1998, 78, i-xv.

[94] Nickoloff, B. J.; Osborne, B. A.; Miele, L. Notch signaling as a therapeutic target in cancer: a new approach to the development of cell fate modifying agents. Oncogene 2003, 22, 6598-6608.

[95] Kopan, R.; Ilagan, M. X. Gamma-secretase: proteasome of the membrane? Nat. Rev. Mol. Cell Biol. 2004, 5, 499-504. 
[96] Wolfe, M. S. The gamma-secretase complex: membrane-embedded proteolytic ensemble. Biochemistry 2006, 45, 7931-7939. 


\section{FIGURE LEGEND}

Fig. (1). Schematic diagram of Notch and androgen signaling pathways in the prostate epithelial cell; possible integration of both pathways during prostate epithelial cell differentiation. Extracellular regions of Notch ligands and receptors interact to activate the receptor, eventually leading to the release of the Notch intracellular domain (NICD). The NICD then translocates to the nucleus and binds to the CSL transcription factor, triggering the transcriptional activation of Notch target genes with CSL binding sites (CBS) in their promoters. On the other hand, the androgen receptor (AR) is able to respond to changes in the levels of androgens carried in the bloodstream. In the presence of androgens, the activated AR moves into the nucleus and binds to specific androgen response elements (AREs) present in the promoters of target genes, activating their transcription. Other signaling mechanisms, including growth factor-, cytokine-, MAPK- and Wnt-dependent signaling also participate in the regulation of prostate epithelial cell biology. Therapeutic modulation of Notch pathway can in theory be achieved by targeting the interaction between Notch ligands and receptors, the proteolytic release of the active NICD or NICD transcriptional functions. Prostate cancer hormonal therapy combines androgen elimination with antiandrogen treatment. Simultaneous targeting of Notch and androgen signaling pathways may potentially improve the outcome of some patients with prostate cancer. Shown below is a scheme with the expression profiles of Notch and androgen receptors in normal prostate epithelial cells during prostate epithelium differentiation. The relative expression levels of elements of both pathways vary during prostate cell epithelial differentiation. Prostate tumorigenesis may be associated with abnormal expression of these receptors, or alterations in their normal mechanisms of function. 


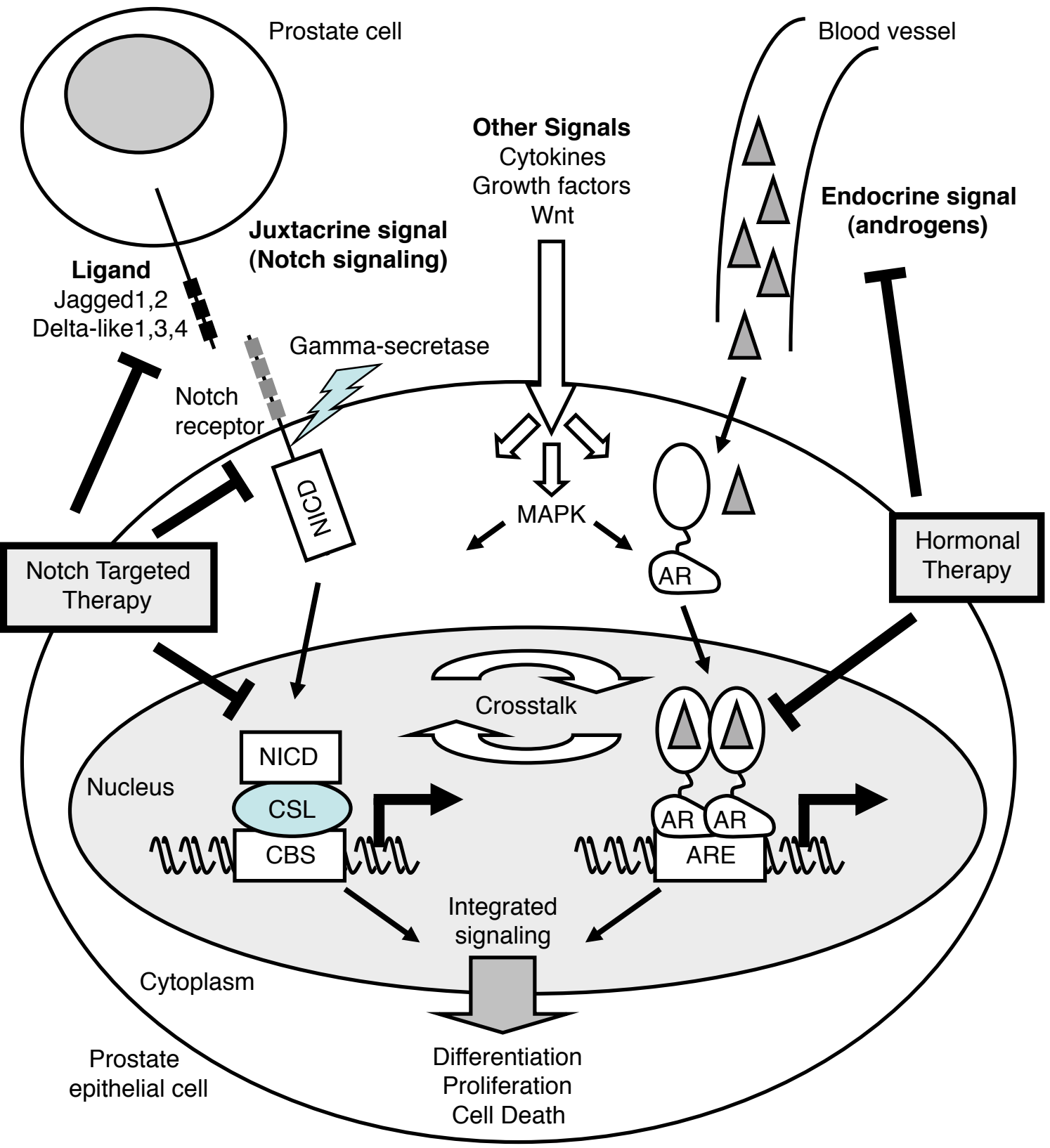

Prostate epithelial cell differentiation

AR expression

Notch expression

\begin{tabular}{|l|l|l|l|}
\hline Stem cells & Transit-amplifying cells & Intermediate cells & Luminal secretory cells \\
\hline
\end{tabular} 
Table 1. Notch signaling in prostate development.

\begin{tabular}{|c|c|}
\hline Experimental model & Phenotype or findings \\
\hline Notch1-GFP transgenic mice & $\begin{array}{l}\text { Notch1 expression is spatially and temporally regulated during } \\
\text { prostatic development }{ }^{\mathrm{a}, \mathrm{b}}\end{array}$ \\
\hline $\begin{array}{l}\text { Normal human prostate epithelial cell } \\
\text { cultures }\end{array}$ & $\begin{array}{l}\text { Notch1 and Jagged1 expression is lost during prostate } \\
\text { epithelial cell differentiation }^{c}\end{array}$ \\
\hline $\begin{array}{l}\text { Human prostate epithelial cells grown in } \\
\text { low-calcium medium }\end{array}$ & $\begin{array}{l}\text { Notch1 is required for survival but prevents differentiation of } \\
\text { transit-amplifying cells }{ }^{\mathrm{d}, \mathrm{e}}\end{array}$ \\
\hline $\begin{array}{l}\text { Androgen-induced regrowth in the } \\
\text { castrated rat ventral prostate }\end{array}$ & $\begin{array}{l}\text { Androgen receptor stimulation in vivo represses Notch } \\
\text { signaling }^{\mathrm{f}}\end{array}$ \\
\hline $\begin{array}{l}\text { Selective ablation of Notch1 expressing } \\
\text { cells in transgenic mice }\end{array}$ & $\begin{array}{l}\text { Ablation of Notch1-expressing cells inhibits prostatic } \\
\text { branching morphogenesis during development and regrowth } \\
\text { following castration and androgen replacement }{ }^{\mathrm{g}}\end{array}$ \\
\hline $\begin{array}{l}\text { Treatment of ex-vivo prostate explants } \\
\text { with inhibitors of gamma-secretase }\end{array}$ & $\begin{array}{l}\text { Inactivation of Notch signaling enhances proliferation but } \\
\text { prevents differentiation of prostate epithelial cells }\end{array}$ \\
\hline $\begin{array}{l}\text { Interferon-inducible Notch1 knockout } \\
\text { mouse model }\end{array}$ & $\begin{array}{l}\text { Deletion of Notch1 increases epithelial cell proliferation and } \\
\text { impairs luminal cell differentiation }^{\mathrm{h}, \mathrm{i}}\end{array}$ \\
\hline
\end{tabular}

Place at the beginning of the "Notch signaling in prostate development" section 
Table 2. Notch signaling in prostate cancer.

\begin{tabular}{|c|c|}
\hline Experimental model & Phenotype or findings \\
\hline $\begin{array}{l}\text { Transgenic Adenocarcinoma of Mouse } \\
\text { Prostate (TRAMP) model }\end{array}$ & $\begin{array}{l}\text { Notch1 expression is elevated in malignant prostatic epithelial } \\
\text { cells }^{\mathrm{a}, \mathrm{b}}\end{array}$ \\
\hline $\begin{array}{l}\text { Human prostate cancer cell lines } \\
\text { (DU145, LNCaP and PC-3) }\end{array}$ & $\begin{array}{l}\text { Constitutive activation of Notch signaling inhibits cell } \\
\text { proliferation }^{\mathrm{b}}\end{array}$ \\
\hline $\begin{array}{l}\text { Osteoblastic skeletal prostate metastatic } \\
\text { cancer cell lines and human clinical } \\
\text { samples from prostate cancer bone } \\
\text { metastases }\end{array}$ & $\begin{array}{l}\text { Notch signaling is required for the development of } \\
\text { osteomimetic properties in prostate cancer bone metastases }^{c}\end{array}$ \\
\hline LNCaP cell line & Jagged 1 is an androgen-regulated gene $e^{\mathrm{d}, \mathrm{e}, \mathrm{f}}$ \\
\hline $\begin{array}{l}\text { Tumor and benign prostate samples from } \\
\text { patients }\end{array}$ & $\begin{array}{l}\text { High Jagged } 1 \text { expression is associated with prostate cancer } \\
\text { metastasis and recurrence }^{\mathrm{f}}\end{array}$ \\
\hline $\begin{array}{l}\text { Human prostate cancer cell lines } \\
\text { (DU145, LNCaP, PC-3 and C4-2B) }\end{array}$ & $\begin{array}{l}\text { Downregulation of Jagged1 induces cell growth inhibition and } \\
\text { S-phase arrest }{ }^{\mathrm{g}}\end{array}$ \\
\hline $\begin{array}{l}\text { Human primary prostate tumors and } \\
\text { benign prostatic hyperplasia samples }\end{array}$ & $\begin{array}{l}\text { HEY1, a mediator of Notch signaling, is excluded from the } \\
\text { nuclei in cancer cells }\end{array}$ \\
\hline $\begin{array}{l}\text { Tumor and benign prostate samples from } \\
\text { patients }\end{array}$ & $\begin{array}{l}\text { NOTCHI and HEYI genes are significantly downregulated in } \\
\text { human prostate adenocarcinomas }\end{array}$ \\
\hline $\begin{array}{l}\text { LADY transgenic mouse model of } \\
\text { prostate cancer }\end{array}$ & $\begin{array}{l}\text { Notch1 expression is increased in developing tumors but not } \\
\text { in the established tumors } \\
{ }^{j}\end{array}$ \\
\hline
\end{tabular}

Place at the beginning of the "NOTCH SIGNALING AND PROSTATE CANCER" section 